\title{
Dynamics analysis of neural univariate time series by recurrence plots
}

Tamara Tošić ${ }^{*}$, Peter beim Graben ${ }^{2,3}$, Kristin K Sellers ${ }^{4}$, Flavio Fröhlich ${ }^{4}$, Axel Hutt ${ }^{1}$

From 24th Annual Computational Neuroscience Meeting: CNS*2015

Prague, Czech Republic. 18-23 July 2015

Transients in non-linear biological signals (e.g., population dynamics or physiological signals) encode an intrinsic behaviour of system dynamics. We study the problem of detecting dynamical transients given a set of signal trials. In general case, different biological signals emerge from different origins and hence exhibit distinct properties that are hard to grasp. For example, to analyze sleep recordings, one considers rhythms of the

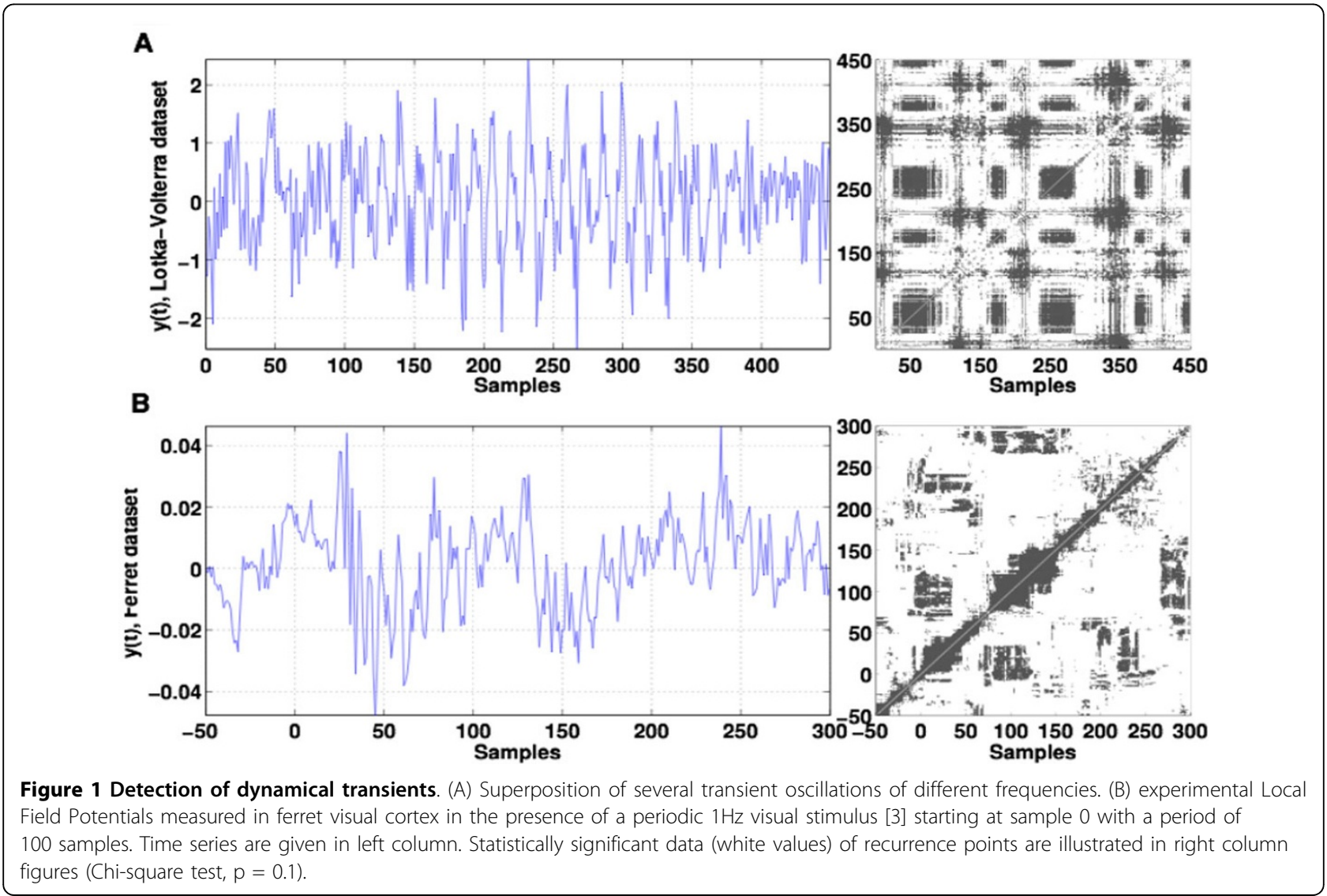

* Correspondence: tamara.tosic@inria.fr

'Inria, CNRS, Loria, UMR no 7503, Vandœuvre-lès-Nancy, F-54500, France

Full list of author information is available at the end of the article 
brain, the cardio-vascular and the respiratory systems. The synchronous analysis of the corresponding time series is an unsolved problem and extracting information from such signals and their trial statistics is challenging. In addition, measurement noise and time jitters between trials may corrupt signals. To attack this demanding problem, we start by a preliminary study of extracting features in multiple trials from univariate time series of the same origin, but without taking into account the common origin. The new method jointly analyzes neural signals by extracting statistical properties, obtained by exploiting the fundamental feature of dynamical systems, the recurrence structure.

Recurrences represent instances in time when the system's trajectory returns to a phase space neighborhood of a location it has visited previously, cf. [1]. Classical recurrence plots (RP) [2] represent symmetric binary valued matrices and characterise the system's phase space. Since neural recurrence patterns occur in particular frequency bands, we propose to build novel, frequency-selective recurrence plots from their time-frequency signal representations. To evaluate the recurrence results, we compute surrogate RPs by time randomisation of the original time-frequency representations. To obtain statistically significant recurrence information, statistics of the original RPs is pixel-wise compared with the surrogate dataset statistics. This novel inference test provides statistically significant pixel values and the corresponding recurrence structure. Results in Figure 1 show an artificial and neural time series and corresponding statistically significant recurrence plots. One observes that the method extracts well several transient oscillations of different frequencies. The analysis of the ferrets data reveals that the first stimulation response at $\mathrm{t}=0 \mathrm{~ms}$ is recurrent to the second response one stimulation period later, while the third response at $t=3 \mathrm{~s}$ is different from the first two. This result indicates temporal neural adaptation during the stimulation.

\section{Acknowledgements}

Research reported in this publication was supported by (1) the LIRA, a research initiative of Fraunhofer Society, Philips and Inria (2) the National Institute Of Mental Health of the National Institutes of Health under Award Number R01MH101547. The content is solely the responsibility of the authors and does not necessarily represent the official views of the National Institutes of Health.

\footnotetext{
Authors' details

${ }^{1}$ Inria, CNRS, Loria, UMR no 7503, Vandœuvre-lès-Nancy, F-54500, France. ${ }^{2}$ Institute of German Studies and Linguistics, Humboldt-University, 10178, Berlin, Germany. ${ }^{3}$ Bernstein Center for Computational Neuroscience, 10178, Berlin, Germany. ${ }^{4}$ University of North Carolina at Chapel Hill, Chapel Hill, 27599, NC, USA.
}

Published: 18 December 2015
References

1. beim Graben $P$, Hutt A: Detecting recurrence domains of dynamical systems by symbolic dynamics. Physical Review Letters 2013, 110(15):154101.

2. Marvan N, Romano MC, Thiel M, Kurths J: Recurrence plots for analysis of complex systems. Physiscs reports 2007, 438:237-329.

3. Sellers KK, Bennett DV, Frohlich F: Frequency-Band Signatures of Visual Responses to Naturalistic Input in Ferret Primary Visual Cortex during Free Viewing. Brain Research 2015, 1598:31-45.

doi:10.1186/1471-2202-16-S1-P105

Cite this article as: Tošić et al:: Dynamics analysis of neural univariate time series by recurrence plots. BMC Neuroscience 2015 16(Suppl 1):P105.

\section{Submit your next manuscript to BioMed Central and take full advantage of:}

- Convenient online submission

- Thorough peer review

- No space constraints or color figure charges

- Immediate publication on acceptance

- Inclusion in PubMed, CAS, Scopus and Google Scholar

- Research which is freely available for redistribution

Submit your manuscript at www.biomedcentral.com/submit 